S. Chersoni ${ }^{1}$, P. Suppa ${ }^{2}$, S. Grandini ${ }^{3}$, C. Goracci ${ }^{3}$, F. Monticelli ${ }^{3}$, C. Yiu ${ }^{4}$, C. Huang ${ }^{5}$, C. Prati ${ }^{1}$, L. Breschi ${ }^{6}$, M. Ferrari ${ }^{3}$, D.H. Pashley ${ }^{7}$, and F.R. Tay ${ }^{4 *}$

${ }^{1}$ Department of Dental Science, University of Bologna, Italy; ${ }^{2}$ Department of Anatomical Science, University of Bologna, Italy; ${ }^{3}$ Department of Dental Materials and Restorative Dentistry, Policlinico 'Le Scotte', University of Siena, Italy; ${ }^{4}$ Pediatric Dentistry and Orthodontics, Faculty of Dentistry, The University of Hong Kong, Prince Philip Dental Hospital, 34 Hospital Road, Hong Kong SAR, China; ${ }^{5}$ College and Hospital of Stomatology, Wuhan University, China; ${ }^{6}$ Department of Surgical Sciences, University of Trieste, Italy; and ${ }^{7}$ Department of Oral Biology and Maxillofacial Pathology, Medical College of Georgia, Augusta, GA, USA; *corresponding author, kfctay@ netvigator.com

J Dent Res 83(6):459-464, 2004

\begin{abstract}
Adhesive dentistry should effectively restore the peripheral seal of dentin after enamel removal. We hypothesize that non-rinsing, simplified, one-step self-etch adhesives are effective for minimizing dentin permeability after tooth preparation procedures. Crown preparations in vital human teeth were sealed with Adper Prompt, Xeno III, iBond, or One-Up Bond F. Epoxy resin replicas were produced from polyvinyl siloxane impressions for SEM examination. Dentin surfaces from extracted human teeth were bonded with these adhesives and connected to a fluidtransport model for permeability measurements and TEM examination. Dentinal fluid droplets were observed from adhesive surfaces in resin replicas of in vivo specimens. In vitro fluid conductance of dentin bonded with one-step selfetch adhesives was either similar to or greater than that of smear-layer-covered dentin. TEM revealed water trees within the adhesives that facilitate water movement across the polymerized, highly permeable adhesives. Both in vitro and in vivo results did not support the proposed hypothesis.
\end{abstract}

KEY WORDS: In vivo, resin replica, permeability, one-step self-etch, water tree.

Received April 4, 2003; Last revision March 18, 2004; Accepted March 24, 2004

A supplemental appendix to this article is published electronically only at http://www.dentalresearch.org.

\section{In vivo and in vitro Permeability of One-step Self-etch Adhesives}

\section{INTRODUCTION}

$A^{n}$ n important goal in conservative dentistry is to restore the peripheral seal of dentin that originally exists prior to the removal of enamel (Pashley et al., 2002). For crown preparations of vital teeth that involve a considerable sacrifice of sound tooth structures, the use of provisional cements may permit more microleakage of bacteria and their products than the final restorations (Baldissara et al., 1998). For preservation of the health of the pulpodentinal complex, an alternative approach is for the exposed dentin to be sealed with resin-based adhesives prior to the taking of impressions (Pashley et al. 1992; Lam and Wilson, 1999; Jayasooriya et al., 2003).

Being non-rinsing, the milder versions of self-etch adhesives preserve smear plugs and prevent the dilution of resin monomers with dentinal fluid (Perdigão, 2002). For the more aggressive self-etch adhesives that completely dissolve smear plugs, coagulation of plasma proteins by primer components may contribute to a reduction in dentin permeability during the processes of simultaneous etching and priming (Nikaido et al., 1995). Although the complete absence of leakage is not a realistic expectation with the use of these adhesives (Tay et al., 2002a), the recent introduction of onestep self-etch adhesives represents a further reduction in working steps that eliminates some of the technique sensitivity and practitioner variability that are associated with the use of total-etch adhesives (Finger and Balkenhol, 1999; Peschke et al., 2000).

Since dentin adhesives are effective in reducing cervical hypersensitivity (Prati et al., 2001), it is prudent to determine if one-step self-etch adhesives can be used for sealing vital teeth following crown preparations. Thus, the objective of this study was to test the hypothesis that one-step self-etch adhesives are effective in reducing dentin permeability under in vivo and in vitro conditions.

\section{MATERIALS \& METHODS}

For the in vivo part of the study, 24 vital posterior teeth (maxillary and mandibular premolars and molars from 17 subjects) that required crown preparations for fixed prosthodontics were selected. The age of the subjects ranged from 23 to 42 yrs. Informed consent of the subjects was obtained under an in vivo protocol reviewed and approved by an ethics committee from the University of Bologna.

For the in vitro part of the study, 35 recently extracted human third molars were collected after the patients' informed consent had been obtained under a protocol reviewed and approved by the institutional review board from the Medical College of Georgia. These teeth were stored in a $1 \%$ chloramine $\mathrm{T}$ solution at $4{ }^{\circ} \mathrm{C}$ and used within 1 mo following extraction. We prepared each tooth by first removing the occlusal enamel using a slow-speed saw (Isomet, Buehler Ltd., Lake Bluff, IL, USA) under copious water-cooling. We used 180-grit silicon carbide (SiC) paper to create a smear layer on the exposed dentin surface. 

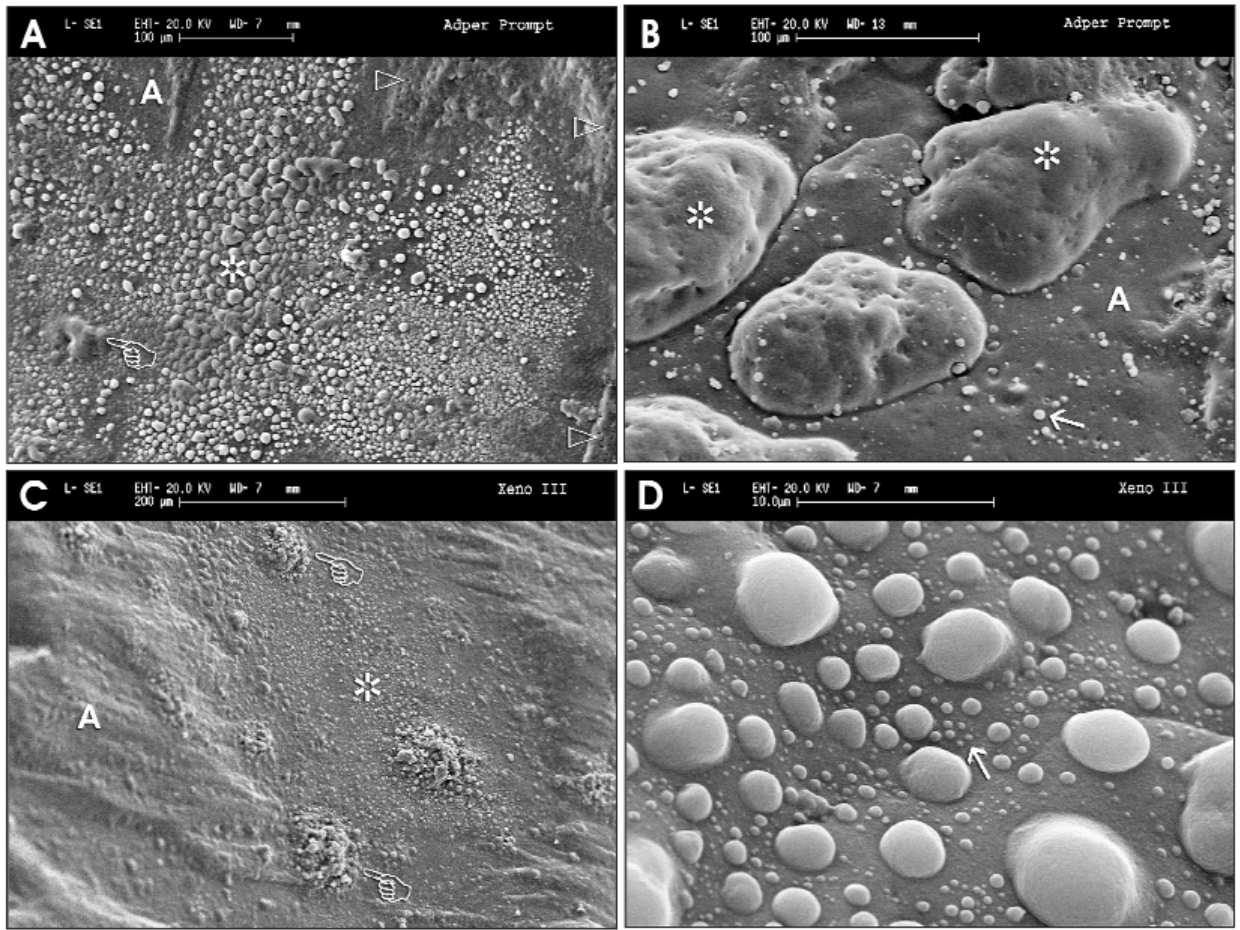

Figure 1. SEM micrographs of epoxy resin replicas of crown preparations of vital human teeth after being bonded with one-step self-etch adhesives Adper Prompt (A-B) and Xeno III (C-D). (A) A low-magnification view of the surface of the adhesive-coated dentin after being sealed with 2 coats of Adper Prompt according to the manufacturer's instructions. The bulk of the dentin surface is covered with adhesive (A), and there are only small areas in which exposed dentinal tubules are observed (open arrowheads). Transudation of dentinal fluid is not evident from the exposed dentinal tubules. However, in areas coated with the adhesive, swelling of the adhesive can be observed (pointer), with transudation of dentinal fluid droplets from the adhesive surface. (B) Pooling of multiple droplets resulted in the appearance of large water bundles (asterisks) over the adhesive surface. Small discrete dentinal fluid droplets can also be found (arrow). (C) A low-magnification view of an epoxy resin replica of the crown preparation of a vital tooth sealed with Xeno III. The dentin surface is completely coated with adhesive (A), and no exposed dentinal tubules are observed. In isolated regions of the crown preparation that probably correspond with areas of deep dentin, swelling of the adhesive layer can be observed (pointers), together with transudation of dentinal fluid over the surface of the adhesive. (D) A high-magnification view of Fig. 1C showing the presence of dentinal fluid droplets over the adhesive surface. No exposed dentinal tubules can be seen. A large number of small, submicron fluid droplets (arrow) can be seen among the larger droplets. material (Affinis LightBody; Colténe AG, Altstätten, Switzerland) with an intra-oral setting time of 3.5 min was used for taking impressions of these crown preparations. After the research impressions were taken, working impressions were then produced for the construction of the fixed prostheses. Research impressions were also prepared for the remaining 4 crown preparations, in which the smear-layer-covered dentin was not bonded with any adhesive. Epoxy resin replicas were produced from these impressions, according to the protocol reported by Itthagarun and Tay (2000). They were sputter-coated with gold/palladium and examined with a SEM (Cambridge Stereoscan 360, Cambridge, United Kingdom) operating at $20 \mathrm{kV}$.

\section{Fluid Conductance Measurements}

We used an in vitro fluid-transport model to measure the fluid conductance through adhesives, following the protocol for hydraulic conductance evaluation reported by Pashley and Depew (1986). The roots were removed from each tooth at $3 \mathrm{~mm}$ below the cemento-enamel junction, by means of the Isomet saw. We gently removed pulpal tissue with a small spoon excavator so as not to touch the predentin. The dentin surface was further abraded until a remaining dentin thickness of $1 \mathrm{~mm}$ was achieved from at least one region of the ground surface to

\section{Experimental Design}

Four one-step self-etch adhesives were examined. They included 3 two-component systems (Adper Prompt, 3M ESPE, St. Paul, MN, USA; Xeno III, Dentsply DeTrey, Konstanz, Germany; One-Up Bond F, Tokuyama Corp., Tokyo, Japan) and 1 single-component system (iBond, Heraeus Kulzer, Hanau, Germany). They were used according to the manufacturers' instructions. A two-step selfetch adhesive (UniFil Bond, GC Corp., Tokyo, Japan) was used as the control. The chemical compositions of these adhesives are shown in Appendix 1.

\section{Scanning Electron Microscopy (SEM)}

For the in vivo part of the study, 4 teeth were randomly assigned to each adhesive group. Following crown preparations under local analgesia (mepivacaine hydrochloride $2 \%$ with adrenaline $1 / 100,000)$, they were sealed with the respective adhesive. The oxygen inhibition layer was gently removed with a cotton pledget soaked in $50 \%$ ethanol. Since it has been shown that impressiontaking does not affect the integrity of the bonded adhesive (Nahon et al., 2001), a low-viscosity polyvinyl siloxane impression the highest pulp horn, as measured with a pair of Iwonson calipers. The crown segment was cemented to a piece of Plexiglass by means of C\&B Metabond (Sun Medical, Shiga, Japan). The Plexiglass was penetrated by a piece of 18-gauge stainless steel tubing that ended flush with the top. This tubing permitted the pulp chamber to be filled with water and to be connected to a waterfilled syringe for measurement of the fluid movement across the dentin surface under $15 \mathrm{~cm}$ of $\mathrm{H}_{2} \mathrm{O}$ pressure (Vongsavan et al., 2000).

We measured fluid conductance $\left(\mu \mathrm{L} / \mathrm{min}^{-1}\right)$ by following the displacement of an air bubble in a micropipette with a constant barrel (Appendix 2). Five teeth were selected at random for each adhesive. For each tooth, fluid conductance was measured three times (Bouillaguet et al., 2000): (a) after dentin was acid-etched for the determination of maximum baseline conductance, (b) after the creation of smear-layer-covered dentin by abrasion of the same tooth with 180-grit SiC paper, and (c) after the dentin was sealed with the respective one-step self-etch adhesive under perfusion at $15 \mathrm{~cm}$ of $\mathrm{H}_{2} \mathrm{O}$ pressure. For each dentin surface, fluid flow $\left(\mu \mathrm{L} / \mathrm{min}^{-1}\right)$ across the smear-layer-covered dentin and bonded 
dentin was expressed as a percentage of that of acid-etched dentin, which was assigned a value of $100 \%$ flow rate. This allowed each specimen to serve as its own control by expressing each of the 3 procedures as a percent of the maximum value, and circumvented the use of surface area for the calculation of hydraulic conductance. Fluid flow for acid-etched dentin was measured for $10 \mathrm{~min}$, and those of smear-layer-covered dentin and bonded dentin for $20 \mathrm{~min}$, with all values corrected to per min. The results were statistically analyzed by two-way analysis of variance [adhesive type and substrate type (i.e., smear-layer-covered dentin $v s$. bonded dentin)] and Tukey's multiple-comparison tests with statistical significance set at $\alpha=0.05$.

\section{Transmission Electron Microscopy (TEM)}

The remaining 10 teeth were used for the second in vitro part of this study, with a resin composite used as an "impression material". Two teeth were selected at random for each adhesive. Each crown segment was similarly connected to the fluid-transport assembly and bonded with the respective adhesive under $15 \mathrm{~cm}$ of $\mathrm{H}_{2} \mathrm{O}$ pressure. A 2-mm-thick layer of microfilled composite (EPICTMPT, Parkell Inc., Farmington, NY, USA) was placed over the cured adhesive under water perfusion. The composite was left in the dark for $3.5 \mathrm{~min}$ to simulate the intra-oral setting time of the impression material. The tooth, coupled with the light-cured composite, was sectioned longitudinally into 1-mm-thick slabs and immersed in a $50 \mathrm{wt} \%$ ammoniacal silver nitrate tracer solution, following the nanoleakage protocol reported by Tay et al. (2002c). Following the reduction of the diamine silver ions into metallic silver, undemineralized, epoxy-resin-embedded, 90-nm-thick sections were prepared and examined with the use of a TEM (Philips EM208S, Philips, Eindhoven, The Netherlands) operated at $80 \mathrm{kV}$.

\section{RESULTS}

Resin replicas of in vivo crown preparations revealed sporadic regions along the surfaces of the adhesive-coated dentin in which there was swelling of the adhesive. For the one-step selfetch adhesives, transudation of dentinal fluid droplets could be universally identified from the surfaces of all resin replicas examined. Adper Prompt exhibited fairly profuse transudation (Fig. 1A), with coalescence of multiple fluid droplets into large water bundles (Fig. 1B). Fluid transudation appeared in localized areas that were close to pulp horns in Xeno III (Fig. $1 \mathrm{C})$, with the presence of myriad small submicron droplets among the larger droplets (Fig. 1D). The extent of dentinal fluid transudation in iBond and One-Up Bond F was comparable with that from the unbonded smearlayer-covered dentin (Fig. 2A). Fluid transudation was not evident in the two-step self-etch adhesive UniFil Bond (Fig. 2B).

Fluid conductance measurements are summarized in the Table. The presence of a smear layer resulted in a reduction of fluid conductance that was only $12-18 \%$ of those recorded for acid-etched dentin. The in vitro fluid conductance of dentin bonded with the 4 one-step self-etch adhesives was
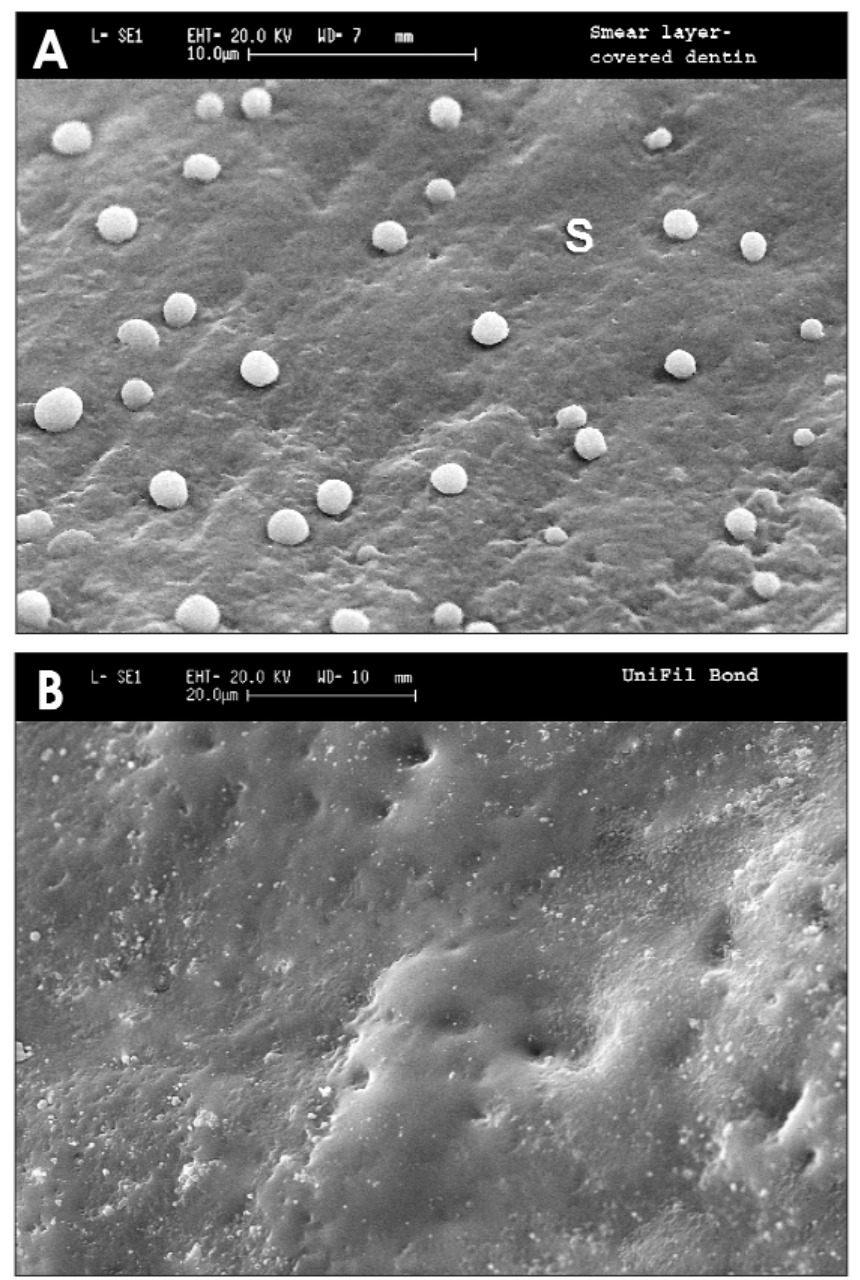

Figure 2. SEM micrographs of epoxy resin replicas of crown preparations of vital human teeth with intact smear layers (A) and after being bonded with the control two-step self-etch adhesive Unifil Bond (B). (A) Unbonded smear-layer-covered dentin (S) showing the transudation of sparse, dentinal fluid droplets trapped by the impression material. (B) An irregular adhesive surface texture is observed after the oxygen inhibition layer was removed in vital deep dentin bonded with the control two-step self-etch adhesive. No transudation of dentinal fluid droplets can be identified.

Table. Fluid Conductance across Dentin during Different Stages of Application of Self-etch Adhesives

Self-etch Adhesive $(\mathrm{N}=5) \quad \begin{gathered}\text { \% Fluid Flow Induced by } 15 \mathrm{~cm} \mathrm{H}_{2} \mathrm{O} \text { of Hydrostatic Pressure } \\ \text { Smear-layer-covered Dentin }\end{gathered}$
Bonded Dentin

\begin{tabular}{llll}
\hline One-step & Adper Prompt & $17.3 \pm 4.5^{\mathrm{A}, 1 *}$ & $28.3 \pm 4.4^{\mathrm{A}, 2}$ \\
& Xeno III & $12.4 \pm 6.2^{\mathrm{A}, 1}$ & $24.2 \pm 2.9^{\mathrm{AB}, 2}$ \\
& iBond & $15.1 \pm 5.6^{\mathrm{A}, 1}$ & $18.7 \pm 3.3^{\mathrm{B}, 1}$ \\
& One-Up Bond F & $14.0 \pm 3.1^{\mathrm{A}, 1}$ & $14.9 \pm 5.0^{\mathrm{B}, 1}$
\end{tabular}

\begin{tabular}{|c|c|c|c|}
\hline $\begin{array}{l}\text { Two-step } \\
\text { (control) }\end{array}$ & $\begin{array}{l}\text { Unifil Bond } \\
\text { (control) }\end{array}$ & $18.2 \pm 5.0^{\mathrm{A}, 1}$ & $2.1 \pm 2.1^{C, 2}$ \\
\hline
\end{tabular}

* Values are means \pm standard deviation. Results of post hoc multiple-comparison tests are indicated by the superscripts. For each column, groups labeled with the same letter superscripts are not significantly different $(P>0.05)$. The differences between smear-layer-covered dentin and bonded dentin for each adhesive are indicated by the row results. For each row, groups labeled with the same numeric superscripts are not significantly different $(P>0.05)$. 


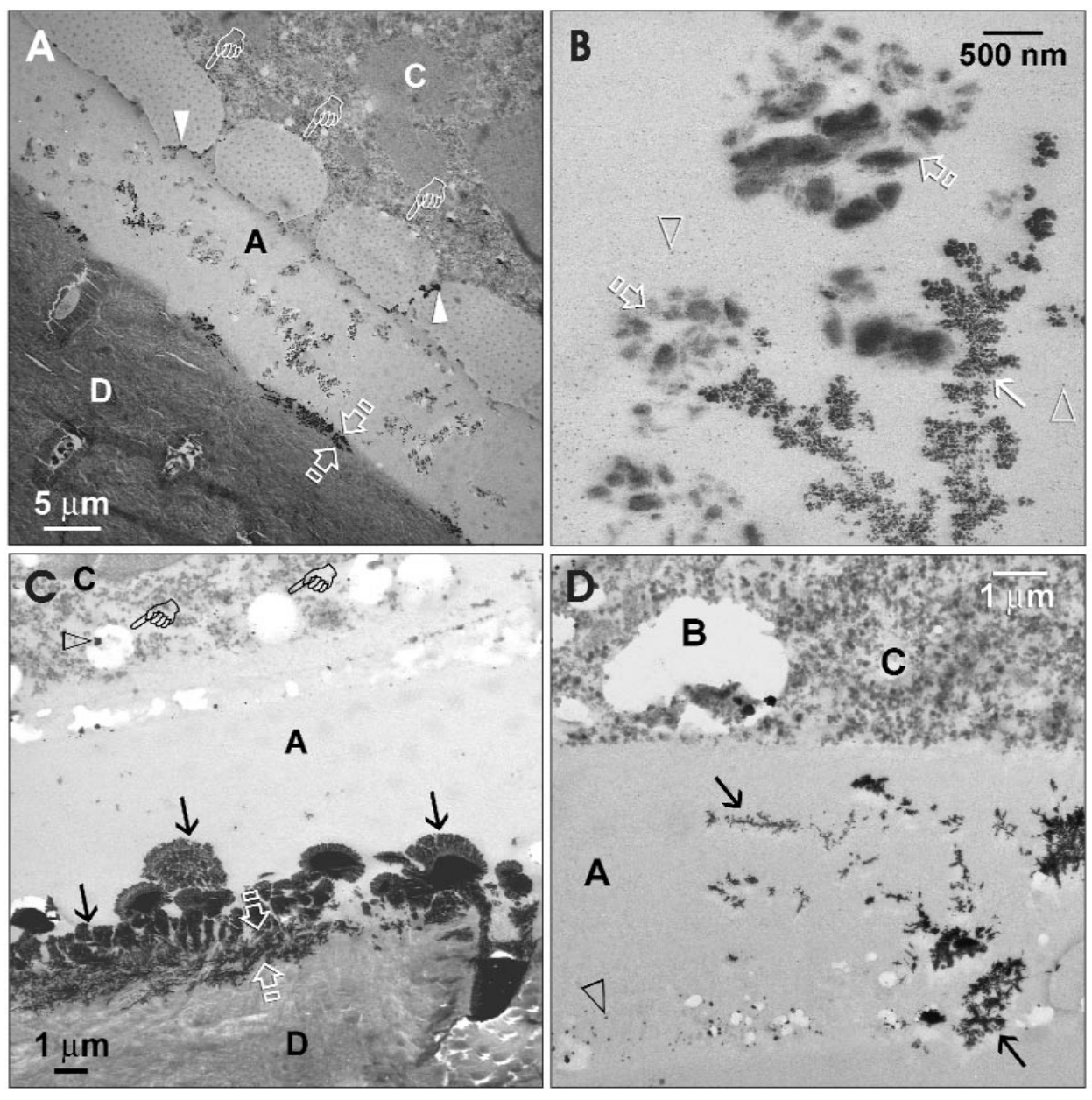

Figure 3. TEM micrographs of unstained, undemineralized resin-dentin interfaces bonded in vitro with One-Up Bond F (A-C) and iBond (D) under a hydrostatic pressure of $15 \mathrm{~cm} \mathrm{H}_{2} \mathrm{O}$ and further coupled to a resin composite under the same pressure in the dark for $3.5 \mathrm{~min}$ before light-activation (to simulate the intra-oral setting time of the impression material). (A) Entrapment of water blisters (pointers) between the adhesive (A) and composite (C) in One-Up Bond F. Silver remnants can be seen along the periphery of some blisters (solid arrowheads), but the majority of the blisters are filled with epoxy resin. A 1- $\mu$ m-thick, partially demineralized hybrid layer can be seen along the adhesive-dentin interface. $D$, intertubular dentin. (B) A high-magnification view of the adhesive layer in One-Up Bond F, showing the existence of a water tree (arrow) among the basic glass filler clusters (open arrows). Very fine, isolated silver grains (open arrowhead) are dispersed throughout the entire adhesive layer. (C) The resin-dentin interface in iBond showing the presence of water blisters (pointers) between the adhesive (A) and the composite (C). Remnant silver deposits (open arrowhead) can be identified with the water blisters. Between open arrows = hybrid layer; arrows = water trees; $D=$ intertubular dentin. (D) A high-magnification view of the adhesive-composite interface in iBond, showing the presence of additional water trees (arrows) and isolated silver grains (open arrowhead) within the bulk of the adhesive (A). Water blisters (B) can be found within the microfilled composite (C). tests are represented in the Table.

For Adper Prompt and Xeno III, separation of sections along the composite-adhesive interfaces occurred during ultramicrotomy, and no intact section could be retrieved. TEM micrographs of One-Up Bond $F$ and iBond bonded under perfusion revealed the presence of water blisters along the composite-adhesive interface (Figs. 3A, 3C), without the loss of integrity between the hybrid layer and the adhesive. Apart from nanoleakage within the hybrid layer, two modes of silver deposition could be identified within the adhesive. Water trees (i.e., silver-filled water channels) extended from the surface of the hybrid layer into the adhesive, and could be observed either adjacent to the basic glass filler clusters (Fig. 3B) or in the unfilled adhesive (Fig. 3D). Fine, isolated silver grains were also present in the adhesive layers (Figs. 3B, 3D). Water blisters were not observed along the adhesive-composite interface in the control two-step self-etch adhesive.

\section{DISCUSSION}

The smear layer and smear plugs account for $86 \%$ of the total resistance to fluid movement in deep dentin (Pashley et al., 1978). Both the in vivo and in vitro results of this study showed that when bonded under dentin perfusion, none of the one-step self-etch adhesives examined was any more effective at sealing dentin than the original smear layer (Gillam et al., 1997). Thus, the hypothesis that one-step self-etch adhesives are effective in reducing dentin permeability must be rejected.

similar to or greater than that of the corresponding smear-layercovered dentin. Conversely, fluid conductance of dentin bonded with the control two-step self-etch adhesive was significantly less than that of the corresponding smear-layercovered dentin $(\mathrm{P}<0.001)$. Two-way ANOVA revealed a significant difference for the factor "substrate type" when the two types of adhesives were pooled for analysis $(P=0.015)$. When the two types of substrates for fluid conductance evaluation were pooled, a highly significant difference was noted for different adhesives $(\mathrm{P}<0.001)$. A significant interaction between "substrate type" and "adhesive type" $(\mathrm{P}<$ 0.001) was also observed. Results of the multiple-comparison
The dentinal fluid droplets that were observed in vivo along the surface of adhesive-bonded dentin were not artifacts produced by moisture condensation during impression-taking, since they were absent when vital dentin was bonded with the control two-step self-etch adhesive. Transudation of dentinal fluid was found to be non-uniform and localized to specific regions, reflecting the variation in permeability from different regions of a crown preparation (Richardson et al., 1991). Moreover, these droplets were absent from epoxy resin replicas of dehydrated dentin bonded in vitro with one-step self-etch adhesives (Chersoni, unpublished results), or from the adhesive-composite interfaces when dentin was replaced with 
processed composite as a bonding substrate (Tay et al., 2003). TEM results further showed that the permeability associated with these adhesives is not caused by a loss of integrity between the adhesive and dentin, but by the presence of water channels (i.e., water trees) that probably expedite such water movement via capillary fluid flow (Tay and Pashley, 2003). Furthermore, the isolated silver grains that were detected throughout the adhesive layer may provide an additional diffusion mechanism for the movement of ions and small molecules across an amorphous polymer matrix based on the free volume theory - via a process known as jump diffusion or ion hopping (Dürr et al., 2002). This study confirms the in vitro model, previously proposed by Tay et al. (2002b), that one-step self-etch adhesive behaves as a permeable membrane after polymerization.

For the two less-permeable adhesives, iBond and One-Up Bond $\mathrm{F}$, in vitro fluid conductance was comparable with that of smear-layer-covered dentin. This may be due to their less aggressive etching effects, that preserve rather than dissolve smear plugs. It is pertinent to note that transudation of dentinal fluid was also observed in vivo for iBond, since this adhesive contains Gluma desensitizer, which is supposed to coagulate plasma proteins (Schüpbach et al., 1997) and form partitions within the dentinal tubules to reduce the dentinal fluid flow (Bergenholtz et al., 1993). The inclusion of cubical/spherical glass fillers in One-Up Bond F or fumed silica fillers in Xeno III did not completely block the paths of water migration through the adhesive, as predicted by the "tortuous path theory" of Nielsen (1967).

Clinically, since water movement through the polymerized adhesive layer involves slow diffusion rather than rapid fluid transport through the dentinal tubules (Mjör and Ferrari, 2002), it is unlikely that their capability for reducing post-operative sensitivity will be affected. However, the results indicate that the new simplified adhesives do not seal dentin very well. If water and small ions can move across the adhesives, one wonders how large molecules must be before their diffusion is restricted. The potential detrimental effect of increased adhesive permeability associated with one-step self-etch adhesives can be seen in low-viscosity self-etching resin cements that contain activator components to render them compatible with acidic adhesives. For those resin cements that utilize one-step self-etching adhesive components, fluid transudation through the adhesive may result in emulsion polymerization of the resin cement to form resin globules under the influence of water (Mak et al., 2002). Adhesive permeability accounts for the compromised bond strength observed when such resin cements were used for bonding to dentin (Carvalho et al., 2004). Conversely, bonding of indirect restorations was improved when dentin was first bonded with a two-step self-etch adhesive prior to impression-taking (Jayasooriya et al., 2003).

\section{ACKNOWLEDGMENTS}

We thank Amy Wong and W.S. Lee, Electron Microscope Unit, the University of Hong Kong, for technical assistance. This study was supported by grant $20003755 / 90800 / 08004 / 400 / 01$, Faculty of Dentistry, the University of Hong Kong, and by grants DE 014911 and DE 015306 (PI. David Pashley) from the National Institute of Dental and Craniofacial Research (Bethesda, MD, USA). The authors are grateful to Zinnia Pang and Kelli Agee for secretarial support.

\section{REFERENCES}

Baldissara P, Comin G, Martone F, Scotti R (1998). Comparative study of the marginal microleakage of six cements in fixed provisional crowns. J Prosthet Dent 80:417-422.

Bergenholtz G, Jontell M, Tuttle A, Knutsson G (1993). Inhibition of serum albumin flux across exposed dentine following conditioning with GLUMA primer, glutaraldehyde or potassium oxalates. $J$ Dent 21:220-227.

Bouillaguet S, Duroux B, Ciucchi B, Sano H (2000). Ability of adhesive systems to seal dentin surfaces: an in vitro study. $J$ Adhes Dent 2:201-208.

Carvalho RM, Pegoraro TA, Tay FR, Pegoraro LF, Silva NRFA, Pashley DH (2004). Adhesive permeability affects coupling of resin cements that utilise self-etching primers to dentine. J Dent 32:55-65.

Dürr O, Volz T, Dieterich W, Nitzan A (2002). Dynamic percolation theory for particle diffusion in a polymer network. J Chem Phys 117:441-447.

Finger WJ, Balkenhol M (1999). Practitioner variability effects on dentin bonding with an acetone-based one-bottle adhesive. $J$ Adhes Dent 1:311-314.

Gillam DG, Mordan NJ, Newman HN (1997). The dentin disc surface: a plausible model for dentin physiology and dentin sensitivity evaluation. Adv Dent Res 11:487-501.

Itthagarun A, Tay FR (2000). Self-contamination of deep dentin by dentin fluid. Am J Dent 13:195-200.

Jayasooriya PR, Pereira PN, Nikaido T, Burrow MF, Tagami J (2003). The effect of a "resin coating" on the interfacial adaptation of composite inlays. Oper Dent 28:28-35.

Lam CW, Wilson PR (1999). Crown cementation and pulpal health. Int Endod J 32:249-256.

Mak YF, Lai SCN, Cheung GSP, Chan AWK, Tay FR, Pashley DH (2002). Micro-tensile bond testing of resin cements to dentin and an indirect resin composite. Dent Mater 18:609-621.

Mjör IA, Ferrari M (2002). Pulp-dentin biology in restorative dentistry. Part 6: Reactions to restorative materials, tooth-restoration interfaces, and adhesive techniques. Quintessence Int 33:35-63.

Nahon M, Dentkos TR, Nelson SK, Gardner FM, Rillman EA (2001). 2000 Judson C. Hickey Scientific Writing Award. Effect of impression materials on hybridized dentin. J Prosthet Dent 85:568-574.

Nielsen LE (1967). Models for the permeability of filled polymer system. J Macromol Sci (Chem) A1:929-942.

Nikaido T, Burrow MF, Tagami J, Takatsu T (1995). Effect of pulpal pressure on adhesion of resin composite to dentin: bovine serum versus saline. Quintessence Int 26:221-226.

Pashley DH, Depew DD (1986). Effects of the smear layer, copalite and oxalate on microleakage. Oper Dent 11:95-102.

Pashley DH, Livingston MJ, Greenhill JD (1978). Regional resistance to fluid flow in human dentine, in vitro. Arch Oral Biol 23:807810.

Pashley DH, Pashley EL, Carvalho RM, Tay FR (2002). The effects of dentin permeability on restorative dentistry. Dent Clin North Am 46:211-245.

Pashley EL, Comer RW, Simpson MD, Horner JA, Pashley DH, Caughman WF (1992). Dentin permeability: sealing the dentin in crown preparations. Oper Dent 17:13-20.

Perdigão J (2002). Dentin bonding as a function of dentin structure. 
Dent Clin North Am 46:277-301.

Peschke A, Blunck U, Roulet JF (2000). Influence of incorrect application of a water-based adhesive system on the marginal adaptation of Class V restorations. Am J Dent 13:239-244.

Prati C, Cervellati F, Sanasi V, Montebugnoli L (2001). Treatment of cervical dentin hypersensitivity with resin adhesives: 4-week evaluation. Am J Dent 14:378-382.

Richardson D, Tao L, Pashley DH (1991). Dentin permeability: effects of crown preparation. Int J Prosthodont 4:219-225.

Schüpbach P, Lutz F, Finger WJ (1997). Closing of dentinal tubules by Gluma desensitizer. Eur J Oral Sci 105:414-421.

Tay FR, Pashley DH (2003). Water treeing-a potential mechanism for degradation of dentin adhesives. Am J Dent 16:6-12.

Tay FR, King NM, Chan KM, Pashley DH (2002a). How can nanoleakage occur in self-etching adhesive systems that demineralize and infiltrate simultaneously? J Adhes Dent 4:255269.

Tay FR, Pashley DH, Suh BI, Carvalho RM, Itthagarun A (2002b). Single-step adhesives are permeable membranes. J Dent 30:371382.

Tay FR, Pashley DH, Yoshiyama M (2002c). Two modes of nanoleakage expression in single-step adhesives. $J$ Dent Res 81:472-476.

Tay FR, Pashley DH, Peters MC (2003). Adhesive permeability affects composite coupling to dentin treated with a self-etch adhesive. Oper Dent 28:610-621.

Vongsavan N, Matthews RW, Matthews B (2000). The permeability of human dentine in vitro and in vivo. Arch Oral Biol 45:931-935. 


\section{RESEARCH REPORTS}

\section{Biomaterials \& Bioengineering}

S. Chersoni ${ }^{1}$, P. Suppa ${ }^{2}$, S. Grandini ${ }^{3}$,

C. Goracci ${ }^{3}$, F. Monticelli ${ }^{3}$, C. Yiu ${ }^{4}$,

C. Huang ${ }^{5}$, C. Prati ${ }^{1}$, L. Breschi ${ }^{6}$,

M. Ferrari ${ }^{3}$, D.H. Pashley ${ }^{7}$, and F.R. Tay ${ }^{4 *}$

\section{In vivo and in vitro Permeability of One-step Self-etch Adhesives}

${ }^{1}$ Department of Dental Science, University of Bologna, Italy;

${ }^{2}$ Department of Anatomical Science, University of Bologna,

Italy; ${ }^{3}$ Department of Dental Materials and Restorative

Dentistry, Policlinico 'Le Scotte', University of Siena, Italy;

${ }^{4}$ Pediatric Dentistry and Orthodontics, Faculty of Dentistry,

The University of Hong Kong, Prince Philip Dental Hospital,

34 Hospital Road, Hong Kong SAR, China; ${ }^{5}$ College and

Hospital of Stomatology, Wuhan University, China;

${ }^{6}$ Department of Surgical Sciences, University of Trieste,

Italy; and ${ }^{7}$ Department of Oral Biology and Maxillofacial

Pathology, Medical College of Georgia, Augusta, GA, USA;

*corresponding author, kfctay@netvigator.com

J Dent Res 83(6):459-464, 2004

\section{APPENDICES}

\section{APPENDIX 1}

Compositions and Application Protocols of the Self-etch Adhesives Used in This Study

\begin{tabular}{|c|c|c|c|c|}
\hline Adhesive & Components & Composition & Application Protocol & Manufacturer \\
\hline \multirow[t]{2}{*}{ Adper Prompt } & Blister A & $\begin{array}{l}\text { Methacrylated phosphoric } \\
\text { acid esters, photo-initiator } \\
\text { (camphorquinone), stabilizer }\end{array}$ & $\begin{array}{l}\text { Mix blisters A and B. } \\
\text { Scrub continuously for } 15 \mathrm{sec} \text { and re-apply } \\
\text { until glossy surface appears. Dry thoroughly. }\end{array}$ & $\begin{array}{l}3 \text { M ESPE, St. Paul, } \\
\text { MN, USA }\end{array}$ \\
\hline & Blister B & $\begin{array}{l}\text { Water, complexed fluorides, } \\
\text { stabilizer }\end{array}$ & $\begin{array}{l}\text { Re-apply a second coat (no waiting time). } \\
\text { Dry thoroughly and light-cure. }\end{array}$ & \\
\hline \multirow[t]{2}{*}{ Xeno III } & Universal & $\begin{array}{l}\text { HEMA*, aerosil R-947 } \\
\text { (fumed silica), BHT (stabilizer), } \\
\text { ethanol, water }\end{array}$ & $\begin{array}{l}\text { Mix liquids A and B. Apply mixed adhesive } \\
\text { and leave undisturbed for } 20 \mathrm{sec}\end{array}$ & $\begin{array}{l}\text { Dentsply DeTrey, } \\
\text { Konstanz, Germany }\end{array}$ \\
\hline & Catalyst & $\begin{array}{l}\text { Pyro-EMA-SK, PEM-F, } \\
\text { UDMA, BHT, camphorquinone, } \\
\text { p-dimethyl amine ethyl benzoate } \\
\text { (co-initiator) }\end{array}$ & $\begin{array}{l}\text { Spread adhesive gently for } 2 \mathrm{sec} \text { until no } \\
\text { more flow of the adhesive occurs and } \\
\text { light-cure for } 10 \mathrm{sec}\end{array}$ & \\
\hline \multirow[t]{2}{*}{ One-Up Bond F } & Liquid $\mathrm{A}$ & $\begin{array}{l}\text { Water, HEMA, methyl methacrylate, } \\
\text { coumarin dye, Methacryloyloxyalkyl } \\
\text { acid phosphate, MAC-10 }\end{array}$ & $\begin{array}{l}\text { Mix liquids } A \text { and } B \text {. Apply mixed adhesive } \\
\text { within } 1.5 \text { min after mixing. Leave the mixed } \\
\text { adhesive on dentin for at least } 20 \mathrm{sec} \text {, briefly } \\
\text { air-dry and light-cure for } 10 \mathrm{sec} \text {. }\end{array}$ & $\begin{array}{l}\text { Tokuyama Corp., } \\
\text { Tokyo, Japan }\end{array}$ \\
\hline & Liquid B & $\begin{array}{l}\text { Multifunctional methacrylic monomer, } \\
\text { Fluoroaluminosilicate glass; } \\
\text { Photoinitiator (aryl borate catalyst) }\end{array}$ & & \\
\hline iBond & $\begin{array}{l}\text { Single bottle, } \\
\text { no-mix system }\end{array}$ & $\begin{array}{l}\text { Acetone, water, glutaraldehyde, } \\
\text { 4-META }\end{array}$ & $\begin{array}{l}\text { Apply a minimum of } 3 \text { consecutive coats of } \\
\text { adhesive with no drying in between. Agitate } \\
\text { for } 30 \mathrm{sec} \text {, gently air-dry, and light-cure for } 20 \mathrm{sec} \text {. }\end{array}$ & $\begin{array}{l}\text { Heraeus Kulzer, } \\
\text { Hanau, Germany }\end{array}$ \\
\hline UniFil Bond & $\begin{array}{l}\text { Self-etching primer } \\
\text { Bonding resin }\end{array}$ & $\begin{array}{l}\text { Water, ethanol, 4-MET, HEMA, } \\
\text { UDMA, photoinitiator } \\
\text { HEMA, UDMA, TEGDMA, } \\
\text { silanized fumed silica }\end{array}$ & $\begin{array}{l}\text { Apply Primer, leave undisturbed for } 20 \mathrm{sec} \text {. } \\
\text { Apply Bond, light-cure for } 10 \mathrm{sec} \text {. }\end{array}$ & GC Corp., Tokyo, Japan \\
\hline
\end{tabular}

* Abbreviations: 4-META, 4-methacryloxyethyltrimellitic anhydride; 4-MET, 4-methacryloxyethyltrimellitic acid; BHT, 2,6-di-tert-butyl-p-cresol; BisGMA, (1-methylethylidene)bis[4,1-phenyleneoxy(2-hydroxy-3,1-propanediyl)] bismethacrylate; HEMA, 2-hydroxylethyl methacrylate; MAC-10, Methacryloxyundecane dicarboxylic acid; PEM-F, Penta-methacryl-oxy-ethyl-cyclo-phosphazen-monofluoride; Pyro-EMA-SK, tetra-methacryl-ethylpyrophosphate; and UDMA, urethane dimethacrylate (1,6-dimethacryl-ethyl-oxy-carbonylamino-2,4,4-trimethyl hexane). 


\section{APPENDIX 2}

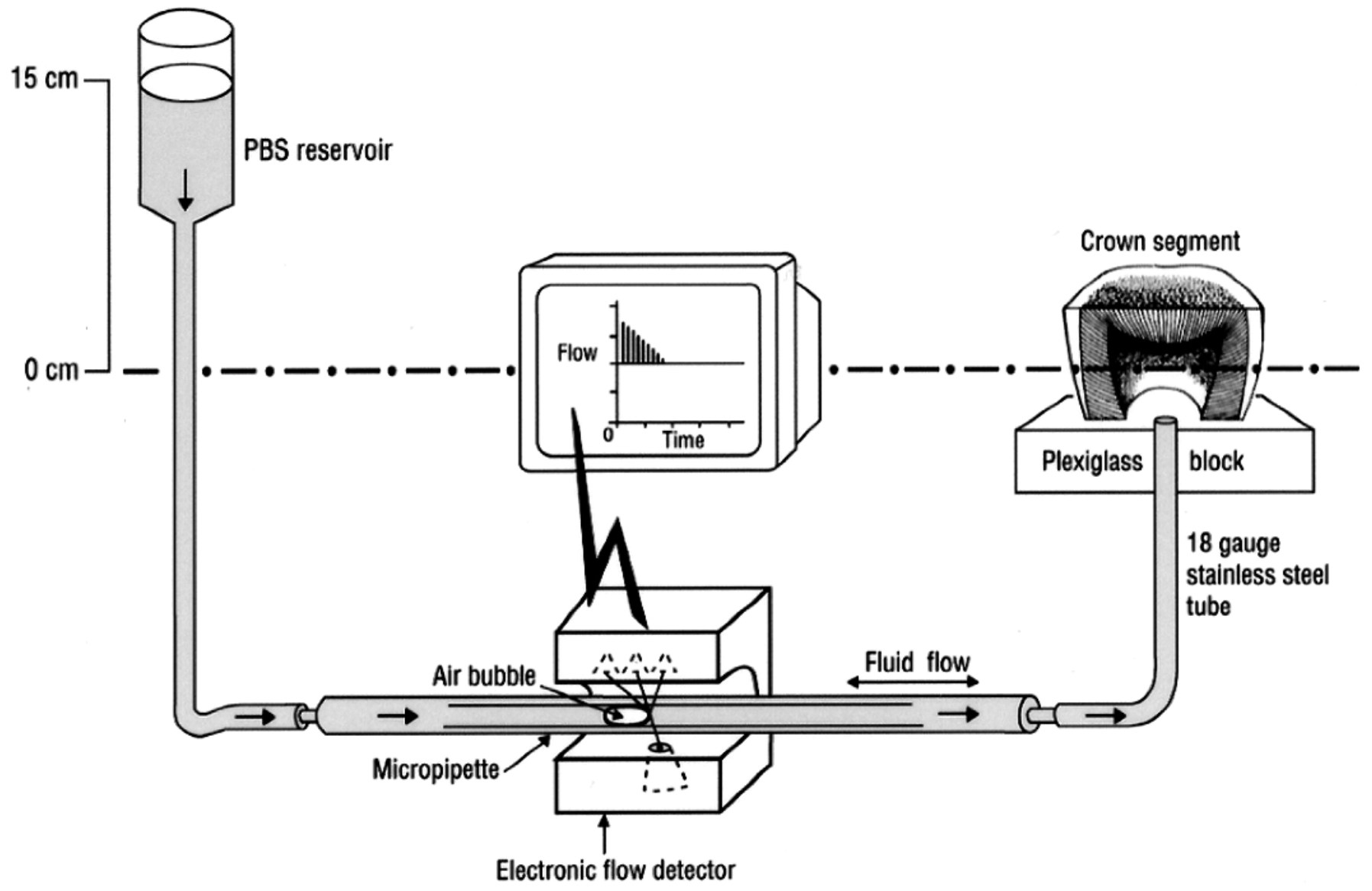

A schematic illustrating the set-up for measuring hydraulic conductance through adhesive-bonded dentin. 